Margaret A. Post*

\title{
Multi-organizational Alliances and Policy Change: Understanding the Mobilization and Impact of Grassroots Coalitions
}

DOI 10.1515/npf-2014-0030

\begin{abstract}
Grassroots coalitions are one mechanism by which marginalized groups access the policy arena. Such alliances integrate group interests in demand making and can influence the policy process through collective action. Understanding what factors lead to formation, sustainability, and success can explain how and why alliances function as political intermediaries. This paper features one national social change organization that collaborates with local grassroots groups working on three federal policy priorities: immigration, retirement security, and economic justice. It investigates what organizational structures and processes increase the access of local organizations to policymakers through multi-organizational alliances of 501(c)(3) and 501(c)(4) organizations. Based on field observations and 58 interviews, the case analysis focuses on inter-organizational partnerships, intra-organizational development, and how these organizational arrangements facilitate grassroots engagement in the policy process. Factors found to impact the strength of alliances include alignment of interests and strategies; an ability to leverage heterogeneous relationships and resources; mutuality, trust, and respect in partnership; political capacity; and "bottom-up" pathways to participation for grassroots constituencies. These findings are central to understanding the structure, function, and political effectiveness of contemporary national-to-local partnerships.
\end{abstract}

Keywords: alliances, coalitions, political capacity, grassroots organizations, policy influence

\section{Introduction}

Intermediary organizations play an essential role in the policymaking process. With activities ranging from public protests to research reports, external groups engage the policy process using diverse strategies for action. They aim to influence policy outcomes, and do so to varying degrees of success. Multi-

*Corresponding author: Margaret A. Post, The Nelson A. Rockefeller Center, Dartmouth College, 6082 Rockefeller Hall, Hanover, NH 03755, USA, E-mail: margaretapost@gmail.com 
organizational alliances are one mechanism by which traditionally marginalized groups access the policy arena.

As external actors, such alliances attempt to influence policy decisions through collective action: they aggregate group interests into demand-making strategies, mobilize shared resources, leverage collective organizational capacity, and garner political will for the changes they want. Policy outcomes vary widely among such efforts, and are also a function of contextual factors in the policy environment. To understand the effectiveness of such organizations one must not only consider policy success or failure but also other forms of influence such as agenda setting, mobilization of interests, constituent representation and voice, public credibility, and the influence of action on legislators' voting records.

This paper explores the question: how do multi-organizational alliances increase the access of grassroots organizations to the federal policy process? It utilizes the case example of a national intermediary organization to build on existing theory about the organizational structures and processes that promote effective alliances for engagement in the policy process. Much of the community organizing scholarship focuses on local and state action with a particular emphasis on impact. Less attention has been paid to how organizational structures and processes can influence and sustain large-scale demand-making strategies. Understanding what organizational factors lead to partnership formation, sustainability, and success in the policy process can explain how and why multiorganizational alliances function as intermediaries of democratic inclusion, particularly between national and local organizations (Andersen and Cohen 2005; Van Dyke and McCammon 2010).

\section{Multi-organizational Alliances as Intermediaries}

A range of social science scholarship examines how external actors organize themselves for collective action in the policymaking process. The notable “Advocacy Coalition Framework" developed by Jenkins-Smith and Sabatier (1993) sets forth much debated theoretical constructs for testing assumptions about how coalitions form, how they are structured over time and under what conditions, and how they relate within the complex ecosystem of the policy arena (Sabatier and Weible 2007; Weible et al. 2011). Another strand of scholarship situates the study of multi-organizational alliances (both informal inter-organizational networks and formal coalitions) in relationship to social movement literature (Andrews and Edwards 2004; Diani and Bison 2004; Jones et al. 2001; Van Dyke and McCammon 2010). For example, Van Dyke and McCammon (2010) 
explore how social ties, interests, identities, ideologies, and political context interact within the formation and maintenance of social movement coalitions. Dixon et al. (2013) look specifically at coalition fit and long-term effectiveness of labor partners within a given movement. They suggest that issues of compatibility and power relationships merit further investigation. Mizrahi and Rosenthal (2001), Roberts-DeGennaro and Mizrahi (2005), and Levi and Murphy (2006) frame multi-organizational alliances within a context of demand making for social change, emphasizing their strategic position to leverage organizational resources and affect outcomes. The field of public health also offers insight about the effectiveness of community-based coalitions for service delivery and the improvement of health outcomes. This literature highlights the practices of pooling diverse resources for collective impact, the necessity of trust and collaboration in partnerships, and the contextual factors that influence coalition formation and maintenance (Foster-Fishman et al. 2001; Kegler et al. 2010; Zakocs and Edwards 2006).

Three themes drawn from this literature are relevant to an analysis of multi-organizational alliances. First, inter-organizational partnerships can be investigated as a type of institutional arrangement used for social and political change (Andrews and Edwards 2004; Baumgartner et al. 2009). These partnerships are built on complex relationships, maintained by specific structures and processes of communication, negotiation, and collective action, and sustained through dynamics of trust, mutuality, and collaboration (Hojnacki 1998; Levi and Murphy 2006; Mizrahi and Rosenthal 2001; Reynolds 2004; Tattersall 2010; Tattersall and Reynolds 2007). Any study of such partnerships must include an analysis of these dimensions. Second, in order to understand the durability of multi-organizational alliances as intermediaries, the political capacity of individual organizations requires attention (Post 2011; Raynor 2011). Participation in an alliance can yield positive and negative outcomes for individual member organizations: alignment with others around a shared agenda can clarify mission and internal goals; staff or members may develop new skills for a particular strategy or set of tasks; new resources from the partnership may yield greater capacity for effectiveness over time (Andrews and Edwards 2004; Ganz 2000; Hojnacki 1998; Hojnacki et al. 2012; Roberts-DeGennaro and Mizrahi 2005). Alternatively, partnerships can deplete the resources and capacities of individual organizations, such as when goals and expectations are unclear or when the self-interest of one entity dominates others (Beamish and Luebbers 2009; Huxham and Vangen 2000; Walker and McCarthy 2010).

Third, the extent to which an alliance can influence change ultimately determines its ability to make claims effectively within the policy arena (see, for example, Gleeson 2013; Tattersall 2010). Indicators of influence include 
different types of outcomes. Much of the literature conceives of policy adoption as the primary benchmark of success. Intermediate outcomes of influence and effectiveness are also relevant, including the ability to build strong coalitions, active participation in agenda setting and legislative drafting, perceived credibility among peer organizations, policymakers, and other actors, and a demonstrated presence at legislative hearings and other public forums (Andrews and Edwards 2004; Hojnacki 1998; Jones et al. 2001; Raynor 2011; Tattersall 2010; Zakocs and Edwards 2006). ${ }^{1}$

This three-prong theoretical framing - inter-organizational partnerships, the intra-organizational development of new skills and capacities, and demandmaking success - is one analytic model for understanding the formation and sustainability of multi-organizational alliances and the role of such alliances as political intermediaries (Post 2011). Because of its focus on organizational processes and structures, this framework is useful for investigating how and why intermediary organizations are able to mediate the interests of local communities as well as garner the political will and grassroots capacity for engagement in the policy process.

\section{Case Background and Methods}

The case example presented in this paper is based on findings from an evaluation study that investigated how one organization - the Center for Community Change (CCC) - develops and sustains the political capacity of local and state organizations to influence the policymaking process. A central aim of the project was to understand how and why the organization strengthens the infrastructure of the progressive movement through its approach to grassroots organizing, collaboration, and policy advocacy. A secondary benefit was its considerable application to theories of organizational effectiveness and influence in the policymaking process. Therefore, the Center is a useful example from which lessons can be drawn about the organizational structures and processes that facilitate the engagement of traditionally marginalized groups in politics. The combination of case description with organizational analysis aims to provide a theoretical and practical understanding of what processes produce stronger engagement in policymaking (Eisenhardt and Graebner 2007; George and Bennett 2005; Sigglekow 2007).

The study was developed in collaboration with the organization's senior leadership to examine its practices of alliance building, organizational

1 For a useful analysis framework intended for practitioner audiences, see Coffman (2009). 
development, and political action with grassroots partners and across policy coalitions. ${ }^{2}$ It was designed using participatory methods in order to yield findings and practical recommendations for the Center's board members, staff, and funders (Brown 2001; McIntyre 2008; Ragin 1994). This approach was intended to enhance organizational learning for improvement. It also was expected to provide a replicable analytic framework for gathering data, understanding impact, and improving practice (Creswell 2013). Therefore, the design was broad in scope and exploratory in nature. It also clarified themes that necessitate further systematic investigation of multi-organizational alliances.

The case draws from multiple data sources, including interviews, participatory field observation, meeting notes, and review of secondary documents. Semistructured interviews were conducted from October 2011 through May 2012. Field observations were conducted in four locations and in several organizational contexts, including two training and campaign strategy sessions, a mid-size convening of local and state partner groups, and a large annual coalition meeting of local, state, and national partner organizations. In total, 58 interviews were conducted with field partners, national allies, and staff members. Respondents were assured of confidentiality and no direct quotations are attributed to any person or organization.

Senior staff members were consulted throughout the research process, including the design of methods, revision of interview protocols, plans for field observations, and the analysis of data. For example, a preliminary list of analytic categories was identified with staff members and based on the organization's strategic goals. These categories guided the initial analysis of interview data and field notes. Staff members then participated in a facilitated discussion analyzing the preliminary interview findings. This analysis was reported internally, employing a thematic review of interview and field notes, secondary documents, and responses from the collective analysis. In addition, a summary document was prepared for wider dissemination to stakeholders, and a facilitated conference call was conducted to share results with respondents and discuss the implications of the findings.

The analytic categories were determined in consultation with senior staff in order to identify issues that would be applicable to organizational priorities and practices (Eisenhardt and Graebner 2007). New categories also emerged from the data that are relevant to theories of alliance formation, activity, and sustainability (Sigglekow 2007). These categories include the following:

2 The CCC is a hybrid organization and the research focused primarily on the activities of its 501(c)(4) entity. However, the organizational structures and processes of the 501(c)(3) were also considered. 
- Robustness (strengths and weaknesses) of strategic alliances

- Collective action techniques and approaches that increase capacity for impact in the policymaking process

- Practices that add value to inter-organizational partnerships and intraorganizational development

- Organizational sustainability

These ideas informed how impact was conceptualized in the analysis. Indicators of impact and influence focus on organizational effectiveness. It was evident in the emergent categories that achieving policy wins is an outcome of significant value. Evidence of strong inter-organizational partnerships, new organizational capacity, engaged diverse constituencies, and organizational sustainability also surfaced as important indicators. Therefore, this paper explains the findings in a context of organizational structure and function so that it can illustrate the strengths and challenges of intermediaries as an organizational form and the effectiveness of alliance building as a strategy for policy engagement.

The limitations of the study include self-reported anecdotes and perceptions in the interview data. To account for these limitations, multiple data sources were used to verify and strengthen the description and to triangulate respondents' impressions and opinions of events. Each interview was placed within an organizational and policy context and matched across field observations and interviews to identify common themes. Additionally, research collaborators at the Center were consulted for accuracy. With the analytic categories identified and defined through a participatory and inductive process, future data collection can employ surveys and assessment tools that measure the impact of particular organizational features on national-to-local partnerships. These factors also can be used to test organizational theories of change and assumptions about the impact of multi-organizational alliances on policy change. In this way, the study has application in both theory and practice.

\section{The CCC: Mobilizing Alliances from 2011 to 2012}

The CCC is a national nonprofit organization (501(c)(3)) that has worked for over 45 years to build the power and civic capacity of low-income communities, especially low-income communities of color. Its primary organizational strategies have been to connect and strengthen grassroots community organizations, to cultivate leadership among staff and constituencies in these organizations, to provide technical assistance for organizational development, and to mobilize groups for civic engagement and political action. Since its founding in 1968, CCC 
has partnered with local, state, and national organizations to achieve change on key social and economic issues.

In 2003, CCC established a 501(c)(4) sister organization - the Center for Community Change Action (CCCAction) ${ }^{3}$ - to advance its advocacy and grassroots organizing strategies. CCC and CCCAction ("the Center") are a hybrid organization with distinct functions. This is a common structure for national intermediary organizations active in the federal policy arena. By establishing a 501(c)(4) organization, the Center expanded its voter engagement and policy advocacy priorities to include direct electoral and legislative action. Central to its mission, the Center engages grassroots constituencies in national issues, leveraging relationships with local organizations for large-scale policy change. In addition to collaborative work with local organizations, the Center also partners with national nonprofit organizations and labor unions for policy change initiatives. Over the last 10 years the Center has taken on national campaigns with coalition partners, including healthcare access, jobs and employment, retirement security, and immigration reform. The Center is one of many organizations working on these issues, yet it acts as a boundary spanner between the field of local grassroots organizations and the national policy environment.

The Center is positioned within the progressive movement as a national intermediary with a track record of partnering with community-based, nonprofit organizations to run local, state, and national policy campaigns. Typically, the Center will form alliances with other organizations because of a shared agenda, complementary expertise in a given issue area, or the ability to connect with grassroots groups most affected by national policy issues. With national allies, like the Service Employees International Union (SEIU) and Gamaliel, a large community organizing network, partnerships enable the groups to leverage broader collective power across constituencies and geographies. By combining efforts, such heterogeneous alliances maximize partners' strengths and resources and are geared toward greater influence in policy making.

The Center also acts as a funder, re-granting funds that support innovations in organizing and the organizational development of small grassroots organizations. Local partners who receive subgrants often describe how the Center aims to align their goals within existing structural models of the organization. Many partner organizations have been able to hire staff or provide additional staff training on national issues as a result of subgrants. In addition to funding,

3 The Center for Community Change Action was known as the Campaign for Community Change until April 2014. This case features the work of CCCAction from 2011 to 2012 that was funded by the Atlantic Philanthropies. 
the Center provides five types of support that are tailored to enhance the capacities of its grassroots partners:

1. Materials and background information on policy issues

2. In-person staff support for strategy development

3. Coaching on communications, fundraising, and online technologies for voter engagement and outreach

4. Training support for leadership development and "movement building"

5. Support for the development of 501(c)(4) organization and activities

The Center works with local and state organizations to anchor grassroots organizing and policy advocacy campaigns within a national context. The relationship between the Center and its partners is intended to be symbiotic, orienting local work toward a national strategy. Field partners recognize that a relationship with the Center enables them to have greater impact. From the Center's perspective, field relationships are the vehicle by which the organization can connect to its core constituencies of low-income people and communities of color. The Center uses in-person convenings as one tool for leveraging and supporting these alliances. As a convener, the Center aims to garner trust among partners and to support lasting infrastructures that yield greater capacity for political action and change. These sessions typically include organizations working on similar issues like retirement security or economic justice to share information, to learn about each other's strategies and practices, and to collaborate on joint advocacy initiatives. For example, within the immigrant rights movement, the Center has served as a hub of information, resources, and communications' expertise and has contributed staff members and significant funding to the campaigns.

\subsection{A Focus on Immigration}

Comprehensive immigration reform has been one of the Center's main policy priorities for over a decade. In 2004, the Center launched and currently staffs and convenes a prominent national coalition for immigrant rights, the Fair Immigration Reform Movement (FIRM). In this role, the Center has collaborated with field partners in 30 states as well as national allies to build grassroots leadership, mobilize organizations, and sustain the movement amidst a divisive, anti-immigrant political environment. The Center supports and trains FIRM organizers, has raised substantial funding from diverse grant makers, and, with other member of the executive committee, is responsible for providing the coalition's strategic vision and leadership. 
FIRM has built a wide and deep infrastructure for the immigrant rights movement through grassroots training, organizational development, and the political mobilization of immigrants and their allies. Since its inception, it has stimulated momentum towards policy change with public actions and legislative lobbying across the United States. Together with labors' unions like SEIU, and other immigrant advocacy groups, such as the National Immigration Forum and United We Dream, FIRM has activated public pressure on federal leaders, including the president, to enact comprehensive immigration reform.

For example, between 2011 and 2012, significant administrative changes were achieved for "The Dreamers," young undocumented immigrants who came to the United States with their families as children. During this time period, FIRM, in partnership with local organizations and other national allies, successfully pressured President Obama to take administrative action in favor of "The Dreamers" by deferring legal action for undocumented childhood arrivals. ${ }^{4}$ The FIRM coalition was relentless in its organizing and activism, regularly engaging in advocacy and civil disobedience. In collaboration with other national labor, faith, and community organizations, the coalition held demonstrations at Congressional offices and on the National Mall that brought together thousands of immigrant families and their allies. A hard-hitting communications strategy was used to reframe the public debate to focus on the contributions of young immigrants, the impact of deportations that separated mixed-status families, and the failings of congressional leaders and the President. In addition, FIRM leaders, including the Center's executive director, Deepak Bhargava, were involved in tense meetings with President Obama at the White House (Wallsten 2012). In spite of continued Congressional gridlock, the DACA decision was viewed as a major advance for the immigrant rights movement toward the possibility of comprehensive immigration reform. ${ }^{5}$

4 Deferred Action for Childhood Arrivals (DACA) was put into effect on June 15, 2012, by executive order for all individuals under age 31 who came to the USA before their 16th birthday and without lawful immigration status.

5 While considerable gains have been made, the fight for comprehensive immigration reform continues. The FIRM Coalition, along with national allies like the Alliance for Citizenship, the National Immigration Forum, and SEIU (to name a few) remain at the forefront of the movement for policy change. However, despite the ongoing direct action efforts of activists and immigration advocates, with ongoing divisions in Congress, and because of dwindling funds from leading philanthropies since 2012, the future of the immigration movement is uncertain. See, for example, Preston (2013). 


\subsection{Building Organizations: Promise Arizona}

In addition to its national coalition work, the Center and FIRM partners have supported the development of new state-based immigrant rights organizations, especially in states that have contended with severely anti-immigrant state legislation. Promise Arizona (PAZ) is one example.

PAZ aims to recruit, train, and develop leaders for political action that will improve the lives of immigrants and their families. ${ }^{6}$ In the wake of Arizona Senate bill, SB1070 (April 2010), long-time organizer, Petra Falcon, and other local immigrant rights activists mobilized a 103-day vigil that galvanized the formation of PAZ. SB1070 and its companion bill, HB 2162, are among the strictest and most controversial anti-immigrant policies in the nation (Morse 2011).

Young people fueled the vigil and ultimately, the development of the organization that would become a vehicle for training leaders in civic engagement, legislative advocacy, and electoral organizing. PAZ was a special project of the Center that served as its fiscal sponsor until 2014. The Center made a longterm commitment to building Arizona's organizing infrastructure for the immigrant rights movement. It invested time, money, and staff in Arizona in order to grow PAZ's resources for leadership development and political action, especially the ongoing fight against the provisions of SB1070. ${ }^{7}$ PAZ also worked closely with the New Organizing Institute to expand its voter engagement strategies and leadership development training approach called "movement building." The collaborative partnership between all three organizations sustained PAZ through its early years of development.

The Center was especially valuable in supporting PAZ's organizational development. Of particular benefits were (1) the engagement of the Center's senior staff in developing strategic direction; (2) mentoring and coaching PAZ staff and members; (3) supporting the organization's communications, training, and fundraising; and (4) focusing on issues of organizational sustainability. This support enabled PAZ to have successful campaigns and to grow as an organization in the midst of a volatile political environment. The Center also helped to build PAZ's 501(c)(4) political action organization and to position it within the national immigrant rights movement and among national funders.

The PAZ infrastructure creates a space in which young people develop handson civic and electoral experience, and, in turn, impact issues that matter to them

\footnotetext{
6 An early version of this example was produced by the author as a working paper for PAZ (Post 2013).

7 The US Supreme Court struck down three provisions of SB1070 in April 2012 in Arizona v. United States, yet immigration status checks by law enforcement remained.
} 
through grassroots organizing. The vigil, voter registration drives, legislative advocacy, the defeat of state Senator Russell Pearce, and voter mobilization strategies indicate that PAZ is changing the anti-immigrant political landscape of Arizona. PAZ also has become a leader in the FIRM network. They participate in the coalition's executive committee and consistently bring members to rallies and demonstrations in Washington, DC. This is one of many examples of how the Center has built a successful alliance with a local organization for national impact.

\subsection{Beyond Immigration}

As the fight for comprehensive immigration reform continued in 2012, the Center targeted two other policy issues: retirement security and jobs and the economy. Similar to partnerships with grassroots' immigrant organizations like PAZ, these partnerships were aimed at supporting local organizations in their effort to influence state and federal policy. Across diverse geographies, organizations received subgrants to support local organizing campaigns. Typically, the organizations funded new or existing staff positions. They focused on the recruitment, training, and retention of local members to engage in advocacy and direct action. Some organizations' grants were supplemented with technical assistance for online communications or specialized leadership development programs like movement building.

The retirement security project included coalition building with national allies (Social Security Works) and establishing a network of local organizations that could influence members of Congress to oppose cuts in social security, Medicare, and Medicaid. A main dimension of their strategy was attempting to shift the debate among lawmakers in key states like Illinois, Iowa, Maine, Minnesota, Missouri, Montana, New Hampshire, Ohio, and Virginia. In these states, the Center supported organizations to develop relationships with legislators as a way of infusing grassroots interests into debates about retirement security policies. Through public testimony and media outreach, the Center and its partners elevated the stories of individuals impacted by program cuts. Using policy education, legislative advocacy, and direct action (like rallies and public disruption), organizations interacted regularly with members of Congress who could support and champion the protection of social security, Medicare, and Medicaid. This process engaged people directly affected by the issue - lowincome seniors, women, and people of color - in the policy process. The Center's work during this time period ultimately led to the launch of Grassroots Ambassadors, a leadership training program for local activists that expanded the national infrastructure of community-based organizations working to improve retirement security policies. 
The Center's work on jobs and the economy was smaller in scale than its retirement security and immigration programs from 2011 to 2012, yet it laid the foundation for the organization's major initiative of the next decade. In the wake of the financial crisis, the Center wanted to develop an agenda to advance economic security for low- and middle-income workers. With a focus on jobs, unemployment, and wages, the Center explored campaign opportunities that could address the long-term effects of the economic downturn. Much of this investment revolved around identifying innovations in grassroots action for policy change at the state and local level. ${ }^{8}$ For example, CCC supported multisector coalitions of faith, labor, and community organizations that attempted to influence the outcomes of policy fights around state budgets (Montana) and collective bargaining rights (Ohio). ${ }^{9}$ The Center also collaborated with national allies such as MoveOn.org and SEIU to target federal policy issues, including public sector job creation, tax cuts, dwindling supports for low-income families, and cuts to retirement security.

Assessing national opportunities to advance a jobs agenda, building alliances with national allies around shared policy priorities, and learning from innovations in grassroots organizing were the groundwork for the Center's new economic justice initiative, launched in 2013. Simultaneous to this exploration, the organization went through an intense internal visioning process. Together with the staff and board of directors, the Center identified a new strategic direction and articulated its long-term goals by aligning policy priorities with appropriate staffing configurations, funding streams, and internal resources necessary for supporting such a vision. The Center was poised at the end of 2012 to carry out its vision of building "scale with soul" so that everyone has "enough to thrive."

The focus of the last decade, particularly on immigration reform, has positioned the Center as a credible national intermediary organization in the

8 The OOC is one such example. OOC is a statewide alliance between community, faith, labor, and policy organizations. OOC's statewide jobs campaign in 2012 and their application of the movement building training approach proved to be a replicable approach for statewide voter mobilization matched with ongoing grassroots engagement beyond the electoral cycle. With financial resources and on-the-ground support from senior staff at the Center, OOC has connected diverse types of organizations, mobilized a statewide campaign around a jobs agenda (public sector job creation, collective bargaining rights, and improved wages), and created a new approach to leadership development and voter engagement in traditionally unorganized constituencies. OOC was one of several organizational partners and national allies that the Center engaged between 2011 and 2012 to develop its current economic justice agenda.

9 In addition to the Center, other national allies supported these campaign initiatives, including National People's Action and the Alliance for a Just Society. 
eyes of its local partners and allies. With major support from the JPB Foundation, the Center now supports an initiative to improve low-wage work, create "good" jobs, and eliminate barriers to employment for formerly incarcerated people. Much of this ambitious work supports local collaborations. However, it is aimed at mobilizing national policy breakthroughs that advance economic justice for low-income people. As a result, the Center continues to convene local and national groups around a common agenda. The Center has also undergone internal re-organization - recruiting new staff expertise, reorienting program teams to fit long-term goals, and developing greater financial sustainability. By raising the salience of poverty and coordinating a national policy effort rooted in grassroots constituencies, the Center strives to ensure that low-income people are central to the debate about how to improve work, create jobs, and catalyze greater economic security.

\section{Discussion}

Because of the Center's long history, depth of experience across policy domains, and diverse relationships with grassroots partners, this case informs both theory and practice about the necessary mechanisms for successful alliances. It illustrates how mutually beneficial partnerships, coalition alignment, political capacity, and leadership development are significant characteristics that contribute to effective grassroots engagement in the policy process. Understanding these factors sheds light on how local-to-national alliances can increase access to the policy arena and the role of intermediary organizations in such a process. Therefore, this discussion focuses on how the Center's position as a national intermediary facilitates greater participation of local grassroots organizations in the policy process. Sustainability and challenges associated with organizational form are also considered (see Table 1 for summary of findings). ${ }^{10}$

In an environment of often loosely connected social change organizations, the Center acts as an intermediary in four ways. First, it builds and supports an infrastructure for grassroots organizing and civic engagement, especially by convening and partnering with local organizations for collective action. Second, it has a proven track record of increasing the capacity of these

10 This discussion extends the theoretical framework developed by Post (2011) that investigates coalition form and behavior in the context of state policy with an analysis of inter-organizational partnerships, intra-organizational development and claims making success. 
Table 1: Summary of findings.

\begin{tabular}{lll}
\hline Themes & Dimensions of alliances \\
\hline 1. Inter-organizational relationships & - & Alignment of interests, goals, and agenda \\
& - & Mutuality \\
& - & Shared investments of funding and technical \\
& & assistance \\
2. Intra-organizational development & - & Ability to convene and mobilize diverse resources \\
& - & Pelitical capacity, knowledge, and skills \\
3. Pathways to participation and demand & - & Lecal-to-national alliance building \\
making & - & Strategic focus on grassroots infrastructure \\
& - & Leadership development and mobilization \\
4. Challenges of organizational form & - & Managing diverse interests and agendas \\
& - & Agility in decision-making \\
& - & Communication \\
& - & Continuity of resources \\
& - & Sustainable organizational leadership \\
\hline
\end{tabular}

organizations for political action. The Center also mobilizes state and local resources for involvement in national policy campaigns. Fourth, through the combined 501(c)(3) and 501(c)(4) structure, the organization works in coalition with other nonprofit and advocacy organizations to influence national policy discussions such as the fight for comprehensive immigration reform and the preservation of retirement security policies.

Partners and national allies interviewed for this study regard the Center as an organization that "thinks big" and advances a powerful model of grassroots' engagement. They acknowledge that no one organization alone can have the kind of impact they want. The Center promotes synergy among groups with common interests, invests heavily in leadership training and organizational development, and mobilizes diverse resources for political impact. As a result, the Center's approach to engagement has increased access for local groups and strengthened their field of action across organizational types (primarily labor, community, and advocacy). This impact is demonstrated through the Center's ability to foster inter-organizational relationships, promote organizational development among local partners, and support the ability of grassroots constituencies to make demands. 


\subsection{Inter-organizational Relationships: Alignment and Mutuality}

Collaboration and partnership are recognized in the nonprofit and philanthropic sectors as essential for winning policy change. ${ }^{11}$ However, grassroots groups, advocacy organizations, and foundations alike often approach political action strategies from varying schools of thought and with disparate interests. Moreover, such groups are typically disconnected, despite philanthropic efforts to promote greater cohesion across fields of action. Differences in organizational culture, structure, and approaches to political engagement affect how groups relate to one another, even if they have shared goals. Alignment, therefore, is a critical dimension of effective alliances.

Achieving any kind of organizational alignment begins with relationship formation. Local organizations that partner with the Center are motivated by the potential for organizational growth, stronger policy and electoral campaigns, and greater power. Interview respondents described four motivations for collaborating with the Center: (1) long-standing or preexisting relationships; (2) a common agenda, shared commitment to a policy issue, or interest in bringing local work to scale; (3) alignment of complementary skills and resources; and (4) subgrants that enables local organizations to join national campaigns. Several respondents noted that the Center's growing reputation as an important national organization in the progressive movement also motivates collaboration, as does the connection with federal policy domains. One national ally commented that it is appealing to work with the Center because of its relationships with funders, its internal culture of experimentation, and its access to other organizations willing to work on national campaigns. These motivations underlie the Center's ability to foster alignment between the interests of grassroots organizations and a national policy agenda.

The Center's investment in partnerships results in alignment around a common purpose and strategy across the three policy domains featured. Such findings are instructive for scholarship on coalitions in that they reveal mechanisms through which intermediaries can foster better alignment in alliances. Three prominent characteristics of alignment from the case example are applicable to the study of alliances:

- Shared commitment to policy goals across organizations

- Common or complementary approaches to political action and organizing

- A mutually agreed upon investment in building strategic capacity across a field of action

11 For examples, see Baumgartner et al. (2009), Jenkins (2006), and Frumkin (2006). 
These characteristics inform how alliances increase access to the policy process. For example, organizations that received retirement security subgrants recognized the Center's willingness to integrate national campaign priorities in light of local goals and that are consistent with local organizing approaches. Interview respondents explained that the Center bases its local strategies and national goals on an in-depth knowledge of local context and by identifying points of connection across groups. As their capacity for political action grew, local organizations were better positioned for national policy engagement. Even with the time it takes to achieve such focus, this kind of alignment increases credibility for an organization and its partners. It also ensures that campaign goals have relevance for local constituencies. In this way, organizations like the Center act as a boundary spanner and intermediary for greater alignment in the field of organizations working to influence the policy process.

Partners described alignment as a function of local organizing in relation to national campaigns. For example, one respondent explained that being involved in a national campaign is beneficial among local members, across the state with other organizations, and with their congressional members who see the organization connected to a larger movement. Congruence between local activities and a national policy agenda enables the organization to be recognized and taken more seriously. One respondent explained that connections with other organizations in the same policy field allow for greater coordination and a more powerful voice in local and national policy debates. Other respondents echoed these themes and spoke about the value of participating in, what they term, national coalition tables. This collective structure allows them to do more effective constituency targeting and increase their impact in the policy process.

Nationally, the Center facilitates better understanding between grassroots groups and the national advocacy community. One respondent described the Center as a grassroots barometer, pointing to the organization's role in aligning local goals with national policy agendas. Another observed how it can be difficult to work with organizations that are not receptive to top-down directives or are not oriented towards a particular kind of advocacy strategy. Respondents repeatedly commented that Center staff are respectful of local leadership, organizing culture, and political context. Others drew on examples of staff members who defended their interests with national coalition partners. In this instance, the Center negotiated between different organizational cultures and increased alignment by fostering understanding of interests and facilitating shifts in practice.

Mutuality in partnership is another dynamic of inter-organizational relationships present in the case. Interview respondents used "mutuality" to explain the 
strength of their relationship with the Center, its staff members, and other organizations connected through the Center. Respect and trust have grown over time, which has increased the mutual benefit of the alliances. Many local partners have a history of collaborating with the Center and with each other. One national ally in immigration reform recognized that the trust they have in the Center evolved through ongoing collaboration and is rooted in confidence in each other's skills, even if they disagree. Other strengths of their relationships included shared values, a common commitment to an issue, and the ability to strategize together.

Alignment is a two-way street. The Center not only mobilizes shared commitment and mutuality between its partners. It also benefits from ongoing dialogue and collaboration with other organizations, and adapts its strategic choices accordingly. Partners understand that their engagement in national policy campaigns as a group enables the Center to leverage credibility with other national organizations and among policymakers. One respondent emphasized that the Center is movement-focused rather than solely focused on its own organizational position. Respondents explained that the Center is a different kind of national partner from typical associations with national organizations. They described the organization as creative, adaptable, and experimental, not limited by one method of organizing or strategy for political action. Respondents made the following observations about the Center as a national partner:

- CCC respects organizational needs to focus locally.

- CCC tries to understand organizational culture and worldview.

- $\quad$ CCC pays attention to local politics and is more likely to be aware of current realities on the ground.

- CCC is willing to negotiate the best use of field partner assets that can advance local or state policy agendas and contribute to national campaigns.

- CCC has a long-term interest and investment in field partners beyond election cycles.

- Sharing information and strategy development occurs in order to leverage greater power, funding, and impact.

These observations indicate how the Center fosters alignment and promotes mutuality in alliances. Because the Center collaborates on strategy development, many local partners feel more engaged in decision-making. They believe they have more flexibility to adapt strategies to their local context than with other campaigns. Some partners experienced the Center as highly effective at developing a collaborative strategy. Others felt that it makes decisions without adequate consultation or before local members are ready to proceed on an 
issue. While the case offers many positive examples of mechanisms that bridge local organizing with national policy advocacy, it also exposes a tension that is inherent to multi-organizational alliances. To what extent is a convening, intermediary organization able to sustain collaborative coalition building at the field level while also moving a political strategy forward within a constantly changing national legislative environment? This question points to an area for further investigation.

\subsection{Political Development}

The development of political capacities is a second prominent feature in the case. Nonprofit organizations that engage in the policy process require a certain level of skill and sophistication to leverage resources needed to influence policy debates, yet many small organizations with direct access to grassroots constituencies often lack such strength and skill. Organizations in coalitions can develop new knowledge and skills that would be otherwise difficult to acquire independently. Inter-organizational partnerships can help organizations advance their goals and grow their capacity for political action. Examining the dynamics of organizational development is useful for understanding how alliances with national intermediaries can strengthen grassroots engagement. Table 2 summarizes these dynamics.

Table 2: Organizational development in local partners.

Organizational supports from national intermediary:

- Subgranted funding and ability to leverage grants with other funders

- Materials and background information on policy issues

- Political expertise and "insider" knowledge

- Intensive, on-the-ground staff support for strategy development

- Coaching on communications and fundraising

- Support for training and adapting organizing curriculum to a local context

Benefits to organizational development:

- Increased knowledge of national policy issues, connections to local concerns, and how to have political influence

- Creative leadership development approaches through "movement building" trainings

- Ability to expand to new constituencies and diversify reach

- Increased capacity for strategy development and political analysis

- Increased knowledge and capacity for communications and fundraising

- Improved infrastructure for electoral organizing and voter mobilization

- New access to online technologies for voter engagement and outreach 
The Center's partners benefit from technical assistance that enhances political action skills. Greater knowledge of federal policy, the ability to educate leaders about the connections between local issues and national policy, and new approaches to training, communications, and fundraising are beneficial to local organizations. Such supports increase their potential for accessing the policy arena and improve the engagement of their grassroots members. For example, the Center's use of "movement-building” training is a vehicle for leadership development that some organizations had not explored previously. Organizations like the Ohio Organizing Collaborative (OOC) and PAZ used movement building trainings and were able to expand to new constituencies, which in turn diversified the organizations' reach and increased their ability to mobilize members.

Another aspect of organizational development is the extent to which the Center supported the growth of electoral and political organizing capacity. This was evident among partners that developed 501(c)(4) organizations to complement existing civic engagement programs. 501(c)(4) organizations are one mechanism by which nonprofit political groups have expanded their engagement in electoral and advocacy campaigns. Many partners also gained new approaches to strategy development, political analysis, and voter mobilization tactics, especially with intensive coaching from senior staff. Finally, respondents value the Center's convening role and benefited from connections with other organizations, "being a part of something larger." These connections enhance their political development. By learning from others and integrating existing political capacities with new strategies introduced by the Center or other partners in the network, local organizations are better positioned to make demands beyond their local context.

\subsection{Pathways to Participation}

Facilitating pathways for grassroots' participation in demand making is a third theme from the case and a key indicator of a national intermediary's ability to be successful over time. As one respondent explained, the Center expands "the visibility, voice, and power of grassroots leadership." While successful legislative and electoral outcomes varied during the time period for this case, it does illustrate how low-income communities of color were integrated into demandmaking strategies through various forms of political action.

Organizations like the Center offer access to resources within certain policy communities and can cultivate leadership among local groups that might otherwise remain isolated from federal policymaking. There are three aspects of local- 
to-national alliances in the case that impact the participation of grassroots' constituencies. First, the alliances expand the scope of influence and credibility among local leaders, other organizations, and public officials. Second, they increase the connection to other groups working on a shared agenda. Third, being part of a local-to-national alliance enhances a strategic focus on the federal policy arena, especially when local interests and national campaign goals are deeply aligned.

Partners are energized by the Center's desire to make connections beyond local work and across the field. Such networks directly benefit local groups. For example, respondents explained that visibility comes with participating in national campaigns. They reported that connections with a national intermediary and organizations in other states energize their membership and increase political credibility, particularly among legislators. In some instances, credibility has given partners' better access to funding sources. Likewise, partners and allies highlighted how working with the Center led to a new understanding of the capacity of local groups to be involved in national policy change. With that, grassroots constituencies benefited from the emphasis on developing local leadership for engagement with federal policy issues.

The Center's role as a convener of FIRM illustrates its impact on grassroots participation. According to one respondent, the immigrant rights movement is stronger because of the involvement of grassroots organizations. This respondent observed a power shift in the immigrant rights movement, suggesting that local groups have become the movement's center of gravity. The combination of intense leadership development, broad mobilization of base constituencies, and pressure on public officials and the president enabled the movement to gain momentum towards administrative and legislative policy change. By equipping organizations with the resources and capacity they need to be successful, the infrastructure of the immigrant rights movement is stronger. Additionally, grassroots leaders now have a more direct pathway to participating in advancing the immigrant rights agenda. In this way, local-to-national relationships as well as grassroots leadership development improve access to participation.

\subsection{Challenges of Organizational Form}

The case illustrates four challenges that are characteristic of intermediary organizations that build multi-organizational alliances. First, intermediary organizations within a national policy context require a high capacity for managing the varied interests and agendas of heterogeneous groups. Because the Center brings local organizations into the national policy arena, its leaders have to 
negotiate how to move a national policy agenda that integrates the voices of grassroots constituencies. The ability to foster mutuality and trust, align the interests of diverse stakeholders, and support political capacity building is critical to buffering this challenge.

Second, managing flows of information can be difficult to coordinate and sustain. For example, respondents explained that good communication depended on which staff members were the main points of contact, and that clear expectations and minimal ambiguity about roles and responsibilities are essential. Not surprisingly, this suggests that skillful and experienced leaders are needed to coordinate information sharing among collaborating groups and to foster high levels of communication.

Agility in decision-making and strategy development is a third challenge of this organizational form. Partners and allies agree that coalition building and intense strategic work takes time and requires cooperation from multiple stakeholders. Some suggest that garnering buy-in and listening well to partners' needs to be balanced with greater focus on campaign goals. While some respondents worried that the Center's decision-making processes are overly cumbersome, they also recognize the organization's rationale for how such processes increase the participation of groups often at the margins of political engagement. One respondent observed that where these processes might encumber some organizations from moving an agenda forward, the Center's leadership manages them well, accounts for various interests at play, and is open to discussing politically charged issues.

Finally, continuity of resources and effective organizational leadership are vital to sustaining local-to-national alliances. Without a secure infrastructure that supports gaps in resources ("lean times") or changes in leadership, an organization's sustainability can weaken. Ongoing financial support of local partnerships is critical to successful collaborations, as is support for organizational development that leads to greater capacity and sustainability. This dynamic was present in the evolution and eventual independence of PAZ and serves as a useful illustration of this challenge.

\section{Conclusion}

The case example illustrates a combination of inter-organizational dynamics, intra-organizational development, and successful grassroots engagement in policy and politics. This combination points to how intermediary organizations improve the policy process by building alliances and catalyzing greater civic 
participation. Effective intermediaries form alliances based on common interests and leverage heterogeneous resources for national impact. They seek mutual benefit across partnerships and mobilize engagement through bottom-up strategies: facilitating partnerships between local and national organizations, strengthening political organizing and advocacy techniques, and cultivating leadership among grassroots constituencies. The findings also suggest that effective multi-organizational alliances are contingent on bridging local and national interests, mobilizing the voice and participation of grassroots constituencies, and providing supports to local organizations that increase capacity for engagement. These theoretical constructs have practical implications for future research and measurement.

Contemporary intermediary organizations play a critical role is spanning the divide between policymaking contexts and the constituencies most affected by the issues. The findings from this study affirm that alliances of grassroots organizations can increase the representation of minority interests in the policymaking process when combined with the resources and credibility of a national intermediary organization. Evidence presented here points to mechanisms that are necessary for the success of multi-organizational alliances in the policy environment. These include (1) alignment of interests and strategies, (2) an ability to leverage heterogeneous relationships and resources; (3) mutuality, trust, and respect in partnership; (4) political capacity building and (5) "bottom-up" pathways to participation for grassroots constituencies. Where such factors were found to add value to the infrastructure of grassroots organizing and policy advocacy, the long-term impact of these structures and processes on sustainable policy change is less conclusive. This is one area for further investigation and requires attention to replicable frameworks for analysis.

An important implication of this study is the insight gained into frameworks for gathering data, understanding impact, and improving the practices of intermediary organizations. Because the research process occurred within a participatory framework and in close connection with the featured organization, the findings are framed within the everyday practices of grassroots activists and nonprofit leaders who seek to engage in the policy process. The analysis provides a picture of how to measure success and sustainability. Table 3 demonstrates one option for how to translate the findings from this study into a measurement framework that can be tested in other cases of local-to-national alliances. Such frameworks are intended to advance understanding of the structure, function, and political effectiveness of contemporary intermediary organizations. 
Table 3: Measuring success in multi-organizational alliances.

\begin{tabular}{|c|c|}
\hline Indicators & Metrics \\
\hline Inter-organizational dynamics & $\begin{array}{ll}- & \text { Mix of organizational type } \\
- & \text { Diversity of skills and resources } \\
- & \text { Alignment of interests and strategies } \\
- & \text { Degrees of accountability } \\
- & \text { Mutuality and trust in coalition }\end{array}$ \\
\hline Intra-organizational development & $\begin{array}{ll}\text { - } & \text { Investments of time and resources in local organizations } \\
\text { - } & \text { New skills, training models, and political tactics } \\
\text { - } & \text { Recruitment, training, and mobilization of members }\end{array}$ \\
\hline Effectiveness & $\begin{array}{ll}\text { - } & \text { Policy wins } \\
\text { - } & \text { Evidence of strong coalition infrastructure } \\
\text { - } & \text { Evidence of political capacity in alliance } \\
\text { - } & \text { Existence of pathways for participation } \\
\text { - } & \text { Grassroots leadership engaged in political action } \\
\text { - } & \text { Ability to leverage diverse resources }\end{array}$ \\
\hline
\end{tabular}

Acknowledgments: The author wishes to thank the editors and anonymous reviewers of Nonprofit Policy Forum as well as Marc Dixon, Lynn Kanter, Mary Lassen, and Melissa Stone for their valuable feedback on the development of this paper.

\section{References}

Anderson, K., and E. Cohen. 2005. "Political Institutions and Incorporation of Immigrants." In In the Politics of Democratic Inclusion, edited by C. Wolbrecht, and R. E. Hero, 186-205. Philadelphia, PA: Temple University Press.

Andrews, K. T., and B. Edwards. 2004. "Advocacy Organizations in the U.S. Political Process." Annual Review of Sociology 30:479-506.

Baumgartner, F. R., J. M. Berry, M. Hojnacki, D. C. Kimball, and B. L. Leech. 2009. Lobbying and Policy Change: Who Wins, Who Loses, and Why. Chicago, London: University of Chicago Press.

Beamish, T. D., and A. J. Luebbers. 2009. "Alliance Building across Social Movements: Bridging Difference in a Peace and Justice Coalition.” Social Problems 56 (4):647-76.

Brown, L. D., ed. 2001. Practice-Research Engagement and Civil Society in a Globalizing World. Cambridge, MA: Hauser Center for Nonprofit Organizations.

Coffman, J. 2009. A User's Guide to Advocacy Evaluation Planning. The Harvard Family Research Project.

Craig, J. ,J. 2006. "Nonprofit Organizations and Political Advocacy." In The Nonprofit Sector: A Research Handbook, edited by W. W. Powell, and R. Steinberg, 2nd ed., 307-32. New Haven, CT: Yale University Press. 
Creswell, J. W. 2013. Qualitative Inquiry and Research Design: Choosing among Five Approaches. Los Angeles, CA: SAGE Publications.

Diani, M., and I. Bison. 2004. "Organizations, Coalitions, and Movements." Theory and Society 33 (3/4) Special Issue: Current Routes to the Study of Contentious Politics and Social Change) (Jun.-Aug):281-309.

Dixon, M., W. F. Danaher, and B. L. Kail. 2013. "Allies, Targets, and the Effectiveness of Coalition Protest: A Comparative Analysis of Labor Unrest in the US South." Mobilization 18 (3):331-50.

Eisenhardt, K. M., and M. E. Graebner. 2007. "Theory Building from Cases: Opportunities and Challenges." The Academy of Management Journal 50 (1):25-32.

Foster-Fishman, P. G., S. L. Berkowitz, D. W. Lounsbury, J. Stephanie, and N. A. Allen. 2001. "Building Collaborative Capacity in Community Coalitions: A Review and Integrative Framework." American Journal of Community Psychology 29 (2):241-61.

Frumkin, P. 2006. Strategic Giving: The Art and Science of Philanthropy. Chicago: University of Chicago Press.

Ganz, M. 2000. "Resources and Resourcefulness: Strategic Capacity in the Unionization of California Agriculture, 1959-1966." American Journal of Sociology 105 (4):1003-62.

George, A. L., and A. Bennett. 2005. Case Studies and Theory Development in the Social Sciences. Cambridge, MA: MIT Press.

Gleeson, S. 2013. "Shifting Agendas, Evolving Coalitions: Advocating for Immigrant Worker Rights in Houston." WorkingUSA 16 (2):207-26.

Hojnacki, M. 1998. “Organized Interests' Advocacy Behavior in Alliances.” Political Research Quarterly 51 (2):437-59.

Hojnacki, M., D. C. Kimball, F. R. Baumgartner, J. M. Berry, and B. L. Leech. 2012. "Studying Organizational Advocacy and Influence: Reexamining Interest Group Research." Annual Review of Political Science 15 (6):379-99.

Huxham, C., and S. Vangen. 2000. "Ambiguity, Complexity and Dynamics in the Membership of Collaboration.” Human Relations 53 (6):771-806.

Jenkins-Smith, H. C., and P. A. Sabatier. 1993. Policy Change and Learning: An Advocacy Coalition Approach. Theoretical Lenses on Public Policy. Boulder, CO. Westview Press.

Jenkins, J. Craig. 2006. "Nonprofit Organizations and Political Advocacy." In The Nonprofit Sector: A Research Handbook, edited by W. W. Powell, and R. Steinberg, 2nd ed., 307-32. New Haven: Yale University Press.

Jones, A. W., R. N. Hutchinson, N. Van Dyke, L. Gates, and M. Companion. 2001. “Coalition Form and Mobilization Effectiveness in Local Social Movements." Sociological Spectrum 21 (2):207-31.

Kegler, M. C., J. Rigler, and S. Honeycutt. 2010. "How Does Community Context Influence Coalitions in the Formation Stage? A Multiple Case Study Based on the Community Coalition Action Theory." BMC Public Health 10 (01):90-100.

Levi, M., and G. H. Murphy. 2006. "Coalitions of Contention: The Case of the WTO Protests in Seattle.” Political Studies 54 (4):651-70.

McIntyre, A. 2008. Participatory Action Research. Qualitative Research Methods Series 52. Los Angeles, CA: Sage Publications.

Mizrahi, T., and B. B. Rosenthal. 2001. "Complexities of Coalition Building: Leaders' Successes, Strategies, Struggles and Solutions." Social Work 46 (1):63-78.

Morse, A. 2011. "Arizona's Immigration Enforcement Laws. Web Resource. National Conference of State Legislatures." Accessed March 24, 2015. http://www.ncsl.org/research/immigration/ analysis-of-arizonas-immigration-law.aspx\#Summary_of_SB1070_and_HB2162. 
Post, Margaret A. 2011. Grassroots Coalitions and State Policy Change: Organizing for Immigrant Health Care. The New Americans: Recent Immigration and American Society. El Paso, TX: LFB Scholarly Pub.

Post, Margaret A. 2013. "Promise Arizona: Building Immigrant Political Power." Working Paper, Promise Arizona and the Center for Community Change.

Preston, J. 2013. "Advocates for Immigrants Up the Ante in a Capitol Sit-In That Brings Arrests." The New York Times August 2, 2013, sec A: 10.

Ragin, C. C. 1994. Constructing Social Research: The Unity and Diversity of Method. Sociology for a New Century; Variation: Sociology for a New Century. Thousand Oaks, CA: Pine Forge Press.

Raynor, J. 2011 "What Makes an Effective Coalition?: Evidence-Based Indicators of Success." Working Paper, The California Endowment.

Reynolds, D. B. 2004. Partnering for Change: Unions and Community Groups Build Coalitions for Economic Justice. Armonk, NY: M.E. Sharpe.

Roberts-Degennaro, M., and T. Mizrahi. 2005. "Coalitions as Social Change Agents." In Handbook of Community Practice, edited by M. Weil and M. Reisch, 305-18. Thousand Oaks, CA: Sage Publications.

Sabatier, P. A., and C. M. Weible. 2007. "The Advocacy Coalition Framework: Innovations and Clarifications." In Theories of the Policy Process, edited by P. A. Sabatier, 2nd ed., 189-220. Boulder, CO: Westview Press.

Siggelkow, N. 2007. "Persuasion with Case Studies." Academy of Management Journal 50 (1):20-4.

Tattersall, A. 2010. Power in Coalition: Strategies for Strong Unions and Social Change. Cornell paperbacks. Ithaca, NY: ILR Press/Cornell University Press.

Tattersall, A., and D. Reynolds. 2007. "The Shifting Power of Labor-Community Coalitions: Identifying Common Elements of Powerful Coalitions in Australia and the U.S." WorkingUSA 10 (1):77, 84, 86-102.

Van Dyke, N., and H. J. McCammon. 2010. Strategic Alliances: Coalition Building and Social Movements. Social Movements, Protest, and Contention, Vol. 34. Minneapolis: University of Minnesota Press.

Walker, E. T., and J. D. McCarthy. 2010. "Legitimacy, Strategy, and Resources in the Survival of Community-Based Organizations.” Social Problems 57 (3):315-40.

Wallsten, P. 2012. “An Uneasy Alliance.” The Washington Post, June 10, 2012, sec A: 1

Weible, C. M., P. A. Sabatier, H. Jenkins-Smith, D. Nohrstedt, A. D. Henry, and P. deLeon. 2011. "A Quarter Century of the Advocacy Coalition Framework: An Introduction to the Special Issue." Policy Studies Journal 39 (3):349-60.

Zakocs, R. C., and E. M. Edwards. 2006. "What Explains Community Coalition Effectiveness?: A Review of the Literature." American Journal of Preventive Medicine 30 (4):351-61.

Note: This paper is based on author findings from an organizational evaluation conducted in 2011-2012. The findings were summarized in an unpublished document for the organization's internal use. Permission to use data has been granted to the author from the organization. 